\title{
INTERNAL FRICTION AND MAGNETIC PROPERTIES OF THERMALLY AGED Fe-1wt.\%Cu ALLOYS
}

\author{
Y. Kamada $^{* a}$, Y. Nishino ${ }^{\text {b }}$, S. Hosoi ${ }^{\text {a }}$, S. Tamaoka ${ }^{\text {b }}$, N. Ide ${ }^{\text {b }}$, H. Kikuchi ${ }^{\text {a }}$, S. Kobayashi ${ }^{\text {a }}$ \\ ${ }^{a}$ NDE \& Science Research Center, Faculty of Engineering, Iwate University, \\ Ueda 4-3-5 Morioka 020-8551, Japan \\ ${ }^{\mathrm{b}}$ Department of Frontier Materials, Nagoya Institute of Technology, \\ Gokiso-cho, Showa-ku, Nagoya 466-8555, Japan
}

*Corresponding author; E-mail: kamada@iwate-u.ac.jp, Tel\&Fax: +81-19-621-6431

Address: 4-3-5 Ueda, Morioka, 020-8551, Japan

\begin{abstract}
The purpose of this study is to investigate the internal friction (IF) behaviour of thermally aged $\mathrm{Fe}-\mathrm{Cu}$ alloys that are model specimens simulating for the irradiation embrittlement of nuclear reactor pressure vessel (RPV) steels. Plate-shaped specimens of $\mathrm{Fe}-1 \mathrm{wt} . \% \mathrm{Cu}$ alloy were quenched from $1123 \mathrm{~K}$ and thermally aged at $773 \mathrm{~K}$ for $10^{3} \mathrm{~min}$. The IF of the specimens was measured without magnetic field using the free resonant bending vibration method. Magnetic hysteresis loops and conductivity was also measured. The IF value, hysteresis loss, and conductivity increased under thermal aging, which suggests that the IF characteristics are closely related to the change of electromagnetic eddy-current loss due to the depletion of $\mathrm{Cu}$ solute atoms. This study demonstrates the possibility of the application of IF measurement as one of the tools for nondestructive characterization of degradation processes of irradiated RPV steels.
\end{abstract}

Keywords - internal friction, magnetism, hysteresis loss, precipitation, thermal aging, irradiation embrittlement 


\section{INTRODUCTION}

It is known that $\mathrm{Cu}$ precipitation is one of the sources of irradiation embrittlement of reactor pressure vessel (RPV) steels at nuclear power plants [1-3]. The clarification of the degradation mechanism and the development of nondestructive evaluation (NDE) techniques are important for prolonging the lifetime of present power plants. Since the magnetic properties are sensitive to the various types of lattice defect through the interaction between magnetic domain walls and the defects, the magnetic NDE method is a strong candidate for evaluation of the precipitation state, and hence the irradiation embrittlement. Precipitation effects on magnetic properties have been reported for neutron irradiated RPV steels $[4,5]$ and thermally aged Fe-Cu model alloys [6, 7], which confirms the potential of magnetic characterization. On the other hand, internal friction (IF) measurement also seems to be a powerful tool, and related studies have been reported for irradiated RPV steels [8] and simulated specimens $[9,10]$. In most of the IF studies, a magnetic field was intentionally applied during the measurement for elimination of magnetic effects in order to highlight the interaction between dislocation and solute atoms. Since the IF of ferromagnetic metals is also influenced by magnetic domain wall movement and magnetization rotation [11], elucidation of magnetic effects on IF of $\mathrm{Cu}$ precipitated metals is definitely needed for establishing the fundamentals as an NDE method. The purpose of this study is to investigate the IF behaviour of thermally aged $\mathrm{Fe}-\mathrm{Cu}$ alloys that are model specimens simulating for the irradiated RPV steels from the magnetic point of view. 


\section{EXPERIMENTAL PROCEDURES}

The chemical composition of the $\mathrm{Fe}-1 \mathrm{wt} . \% \mathrm{Cu}$ model alloy used in this study is listed in Table 1 .

The alloy was quenched from $1123 \mathrm{~K}$ for preparing the supersaturated solid-solution state, and cut into two plates $(80 \mathrm{~mm} \times 9 \mathrm{~mm} \times 1 \mathrm{~mm})$. One was used as unaged state, and the other thermally aged at $773 \mathrm{~K}$ for $10^{3} \mathrm{~min}$. The same plate-shaped specimens were used for both IF and magnetic hysteresis loop ( $B-H$ loop) measurements. The experimental setups are shown in Fig. 1

IF was measured in vacuum by means of a free-decay method of flexural vibration at a frequency around $760 \mathrm{~Hz}$ in the fundamental resonant mode (Fig. 1(a)) $[12,13]$. For driving the vibration, an electromagnetic coil was used. However, the magnetic influence of the coil on IF is small, and other external fields were not applied during the measurement. After steady-state vibration, the driving signal was turned off and then a free-decay curve was recorded on a personal computer through an analog-digital converter. As a measure of IF, the logarithmic decrement was determined from the slope of a tangent to the smooth envelope of the free-decay curve as a function of the strain amplitude in the range of $10^{-7}$ to $10^{-5}$.

$B-H$ loops were measured using a U-shaped Fe-Si yoke and lab-made digital loop tracer (Fig.1 (b)). Exciting and detecting coils were wound around the yoke and specimen respectively. Induced voltage signals collected by a preamplifier and low-pass filter were digitalized and integrated to obtain flux density, $B . \quad B-H$ loops were obtained by combining an exciting field, $H$, calculated from a current signal. The exciting frequency was chosen in the range from 0.05 to $1.0 \mathrm{~Hz}$, and magnetization 
dynamics was examined.

For another series of specimens, the dependence of hardness and conductivity on aging time was also investigated. Micro-Vickers hardness test was conducted under a load of $300 \mathrm{~g}$ at five points and then averaged. The electrical conductivity was measured for thin rod specimens by a direct current (DC) four-point method. Structural characterization on typical aged specimens was performed using transmission electron microscopy (TEM). All the above measurements were carried out at room temperature.

\section{RESULTS AND DISCUSSIONS}

Fig. 2 shows the Vickers hardness of the present unaged and $10^{3}$ min-aged $\mathrm{Fe}-\mathrm{Cu}$ alloy specimens against aging time, together with the previous schematic data [7]. The hardness data of the present specimens lie on the curve of previous measurements, both showing a peaking trend against aging time. The peaking trend can be explained by the nucleation of $\mathrm{Cu}$ precipitates, and the change of their crystal structure, size and density [7, 14]. As shown in the inset of Fig. 2, the formation of precipitates of incoherent fcc-Cu was directly confirmed by TEM images for long-time aged specimens. As for short-time aged ones, it was difficult to obtain clear images because of the small size and coherent nature of the precipitates. However, in the $10^{3}$ min-aged specimen, small precipitates of coherent bcc- $\mathrm{Cu}$ and incoherent $9 \mathrm{R}-\mathrm{Cu}$ would co-exist with high density and therefore the hardness became a maximum. 
Fig. 3 shows the strain amplitude dependence of IF for unaged and $10^{3}$ min-aged specimens. In general, IF can be categorized into two parts, amplitude-independent IF (AIDIF) and amplitude-dependent IF (ADIF) [9, 12, 13]. Fig. 3 shows ADIF already appearing at around $10^{-6}$ strain, which is a quite small strain level, compared to nonmagnetic bcc metals [13]. Since similar phenomena have been reported in ferromagnetic metals measured without magnetic field $[9,11]$, the observed IF comes mainly from the loss of magnetic origins. Comparing two specimens, the IF of aged specimen was larger than that of unaged one, which suggests a larger magnetic energy loss of aged specimen rather than a mechanical energy loss due to motion of dislocations.

Fig. 4 shows $B-H$ loops of unaged and $10^{3}$ min-aged specimens measured at 0.05 and $1.0 \mathrm{~Hz}$. In both specimens, the width of $B-H$ loops increases at higher frequency, and a significant change was not observed in the shape of loops by thermal aging. The area inside a $B-H$ loop, called magnetic hysteresis loss, is the energy lost in one cycle of a magnetization process. The frequency dependence of the loss of two specimens is summarized in Fig. 5. The hysteresis loss of both specimens increased with increasing frequency as a result of eddy currents induced in the specimen by the increasingly rapid change in magnetic flux density. The static hysteresis loss - a value interpolated to the zero frequency - is almost the same between the two specimens. However, at high frequency the hysteresis loss of the aged specimen became larger than that of the unaged one. According to the classical theory, the electromagnetic eddy-current loss has a linear dependence on conductivity [15]. To clarify the origin of the increase of eddy-current loss by thermal aging, 
conductivity measurements were carried out.

Fig. 6 shows the aging time dependence of the conductivity of $\mathrm{Fe}-1 \mathrm{wt} . \% \mathrm{Cu}$ specimens, together with the value of pure iron. Before thermal aging, the conductivity of $\mathrm{Fe}-\mathrm{Cu}$ alloy is $20 \%$ smaller than that of pure iron. With increasing aging time, conductivity gradually increased, which is consistent with hardness change as shown in Fig. 2. Contrarily, the conductivity does not show a peaking trend as in the case of hardness, and approaches to the value of iron at the longer aging time. It has been reported that the conductivity of $\mathrm{Fe}-\mathrm{Cu}$ alloys in a solid-solution state decreases linearly with $\mathrm{Cu}$ content due to the electron scattering by $\mathrm{Cu}$ solute atoms [16]. This characteristic suggests that the observed change of conductivity would be a result of matrix solute depletion by thermal aging.

The present study shows that the increase of conductivity due to the solute depletion during precipitation process would enhance the electromagnetic eddy-current loss, and then cause an increase of IF. Further systematic experiments under the controlled external magnetic fields are desirable for quantitative analysis including other factors such as magnetic permeability and magnetostriction, and a detailed consideration of the effects of eddy-current loss on AIDIF and ADIF is necessary [17]; however, the close relation between IF characteristics and $\mathrm{Cu}$ precipitation process was confirmed from magnetic point of view, and this study suggests the possibility of the application of IF measurement as one of the tools for NDE of irradiated RPV steels. 


\section{CONCLUSIONS}

Internal friction and magnetic properties of thermally aged $\mathrm{Fe}-1 \mathrm{wt} . \% \mathrm{Cu}$ alloy were investigated. The IF value and hysteresis loss increased with thermal aging. The conductivity also increased due to solute depletion during the $\mathrm{Cu}$ precipitation process. These results suggest that the IF characteristics are closely related to the change of electromagnetic eddy-current loss due to the reduction of $\mathrm{Cu}$ solute atoms.

\section{ACKNOWLEDGMENT}

This work was supported in part by a Grant-in-Aid for Exploratory Research, No.20656151, from the Ministry of Education, Culture, Sports, Science and Technology of Japan. The authors would like to thank Prof. Echigoya for support of the TEM observations. 


\section{References}

[1] G. R. Odette and G. E. Lucas, Radiat. Eff. Defects Solids, 144 (1998) 189-231.

[2] K. Fukuya, K. Ohno, H. Nakata, S. Dumbill, and J. M. Hyde, J. Nucl. Mater. 312, (2003) 163-173.

[3] Y. Nagai, T. Toyama, Y. Nishiyama, M. Suzuki, Z. Tang and M. Hasegawa, Appl. Phys. Lett. 87 (2005) 261920/1-3.

[4] S. Takahashi, H. Kikuchi, K. Ara, N. Ebine, Y. Kamada, S. Kobayashi and M. Suzuki, J. Appl. Phys. $100(2006) \quad 023902 / 1-6$.

[5] L. Vandenbossche, M. J. Konstantinovic and L. Dupre, J. Magn. Magn. Mater. (2008) in press.

[6] I. Altpeter, G. Dobmann, K.-H. Katerbau, M. Schick, P. Binkele, P. Kizler, and S. Schmauder, Nucl. Eng. Design, 206, (2001) 337-350.

[7] Y. Kamada, D. G. Park, S. Takahashi, H. Kikuchi, S. Kobayashi, K. Ara, J. H. Hong, and I. G. Park, IEEE Trans. Magn. 43 (2007) 2701-2703.

[8] K. Van Ouytsel, R. De Batist, and R. Schaller, Int. J. Pressure Vessels and Piping, 80 (2003) 275-284.

[9] B. K. Kardashev, K. Van Ouytsel, and R. De Batist, J. Alloys Compd. 310 (2000) 169-172.

[10] M. J. Konstantinovic, A. Almazouzi, M. Scibetta, and E van Walle, J. Nucl. Mater. 362 (2007) 283-286.

[11] V. F. Coronel and D. N. Beshers, J. Appl. Phys. 64 (1988) 2006-2015.

[12] Y. Nishino and K. Ikai, Mater. Sci. Eng. A442 (2006) 347-351.

[13] N. Ide, T. Atsumi, and Y. Nishino, Mater. Sci. Eng. A442 (2006) 156-159.

[14] A. Deschamps, M. Militzer, and W. J. Poole, ISIJ International, 41 (2001) 196-205.

[15] R. C. O’ Handley, Modern Magnetic Materials: Principles and Applications, Wiley-Interscience Publication, New York, 2000, 341.

[16] M. H. Mathon, A. Barbu, F. Dunstetter, F. Maury, N. Lorenzelli, and C. H. de Novion, J. Nucl. Mater. 245 (1997) 224-237.

[17] J. Degauque, Mater. Sci. Forum 366-368 (2001) 453-482. 


\section{Captions}

Table 1 Chemical composition (wt.\%) of the Fe-Cu model alloy.

Fig. 1 Schematic representation of the measurement setups.

(a) IF and (b) magnetic hysteresis loop measurements.

Fig. 2 Aging time dependence of the Vickers hardness.

Inset shows typical TEM image after $2 \times 10^{4}$ min-aging.

Fig. 3 Strain amplitude dependence of the internal friction.

Fig. 4 Magnetic hysteresis loops of (a) unaged and (b) aged specimens.

Fig. 5 Magnetic hysteresis loss as a function of frequency.

Fig. 6 Aging time dependence of conductivity. 
Table 1 Chemical composition (wt.\%) of the Fe-Cu model alloy.

\begin{tabular}{ccccccccc}
\hline $\mathrm{C}$ & $\mathrm{Si}$ & $\mathrm{Mn}$ & $\mathrm{P}$ & $\mathrm{S}$ & $\mathrm{Al}$ & $\mathrm{Cu}$ & $\mathrm{N}$ & $\mathrm{O}$ \\
\hline 0.0010 & $<0.01$ & $<0.01$ & 0.001 & 0.0004 & $<0.001$ & 1.03 & 0.0015 & 0.0085 \\
\hline
\end{tabular}

Y. Kamada et al. FM034 

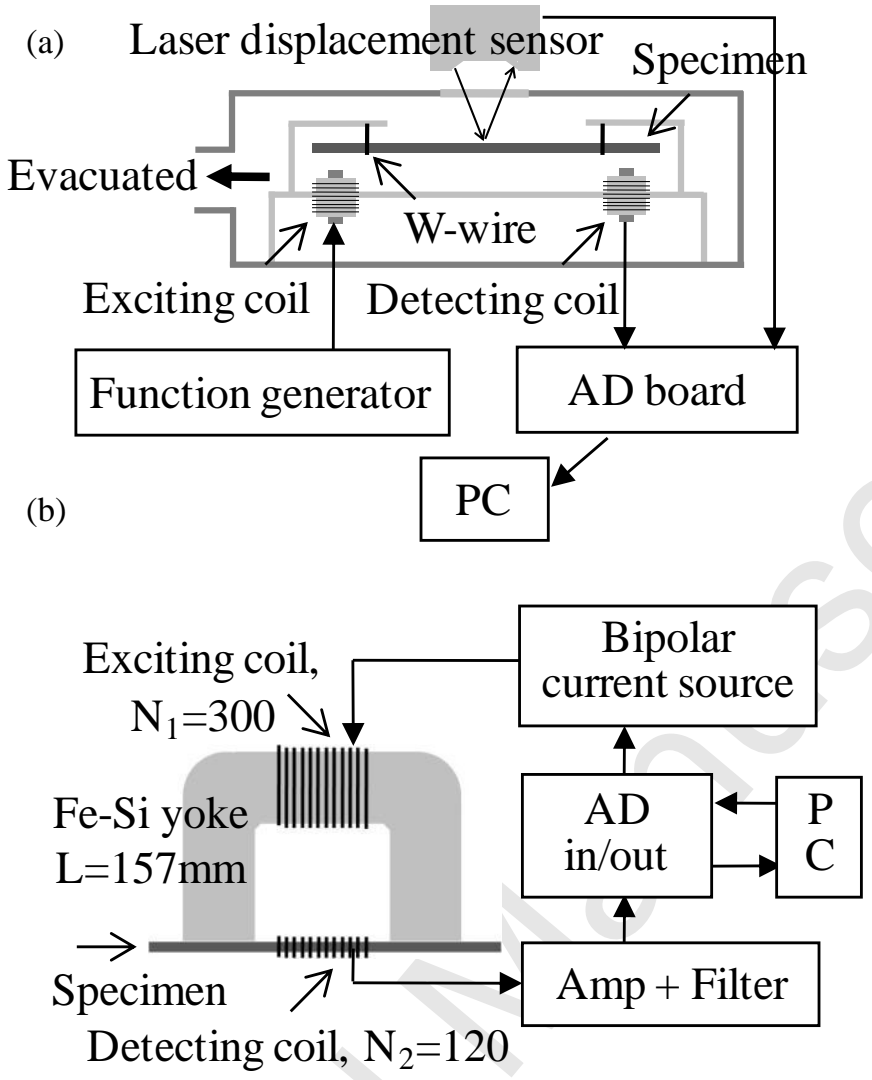

Fig. 1 Schematic representation of the measurement setups.

(a) IF and (b) magnetic hysteresis loop measurements. 


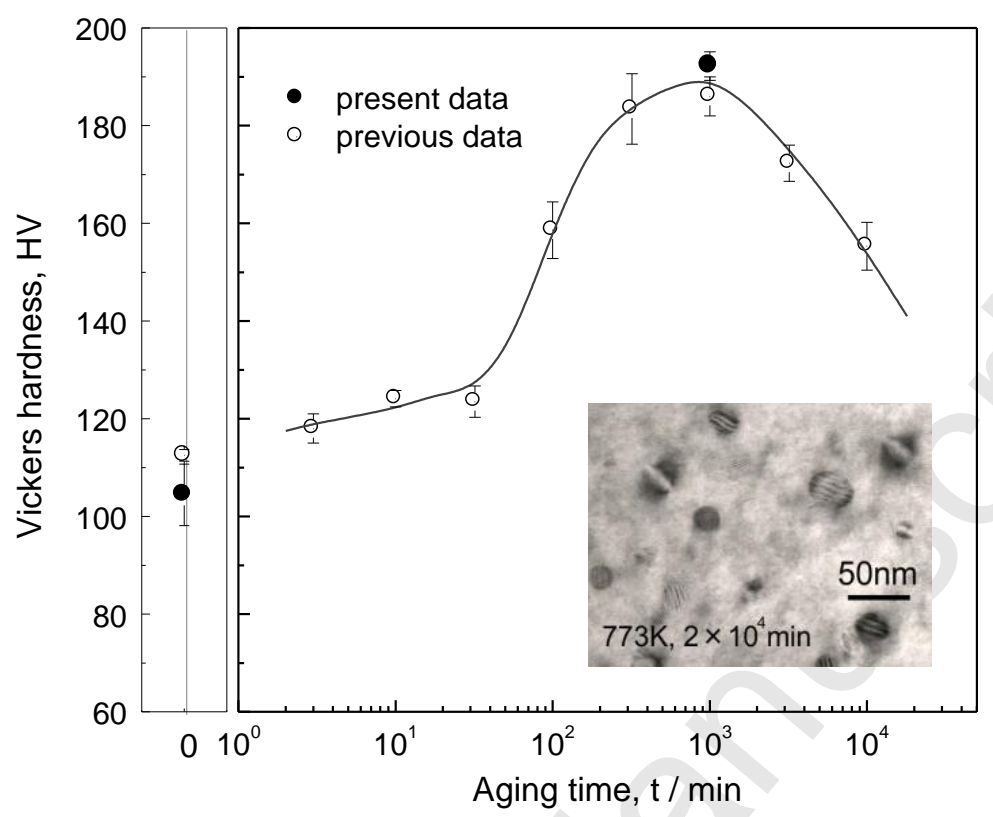

Fig. 2 Aging time dependence of the Vickers hardness. Inset shows typical TEM image after $2 \times 10^{4}$ min-aging. 


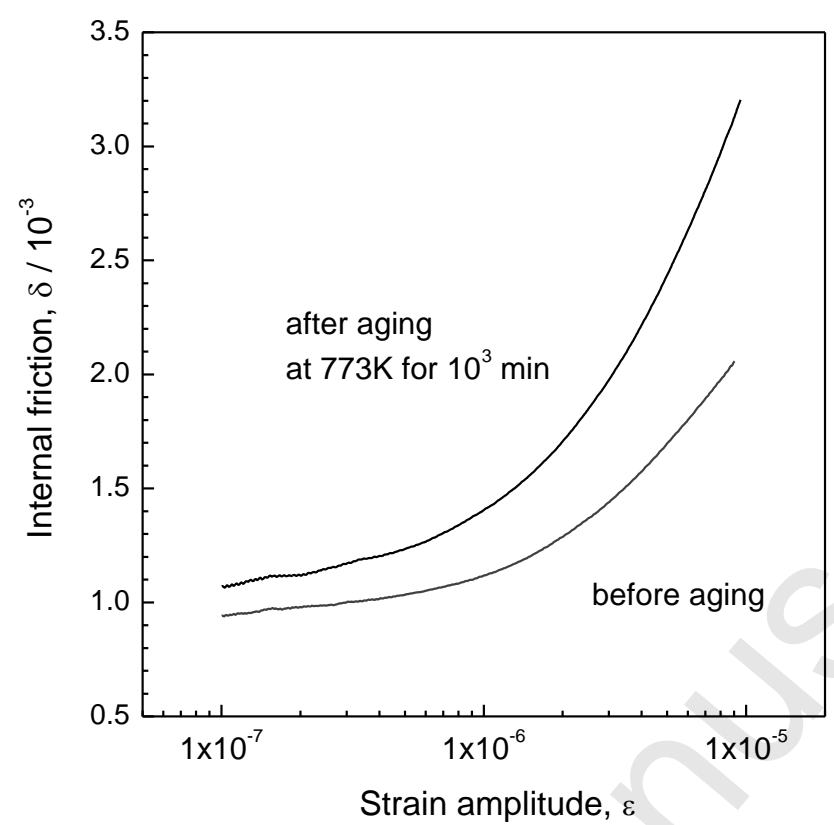

Fig. 3 Strain amplitude dependence of the internal friction.

Y. Kamada et al. FM034 

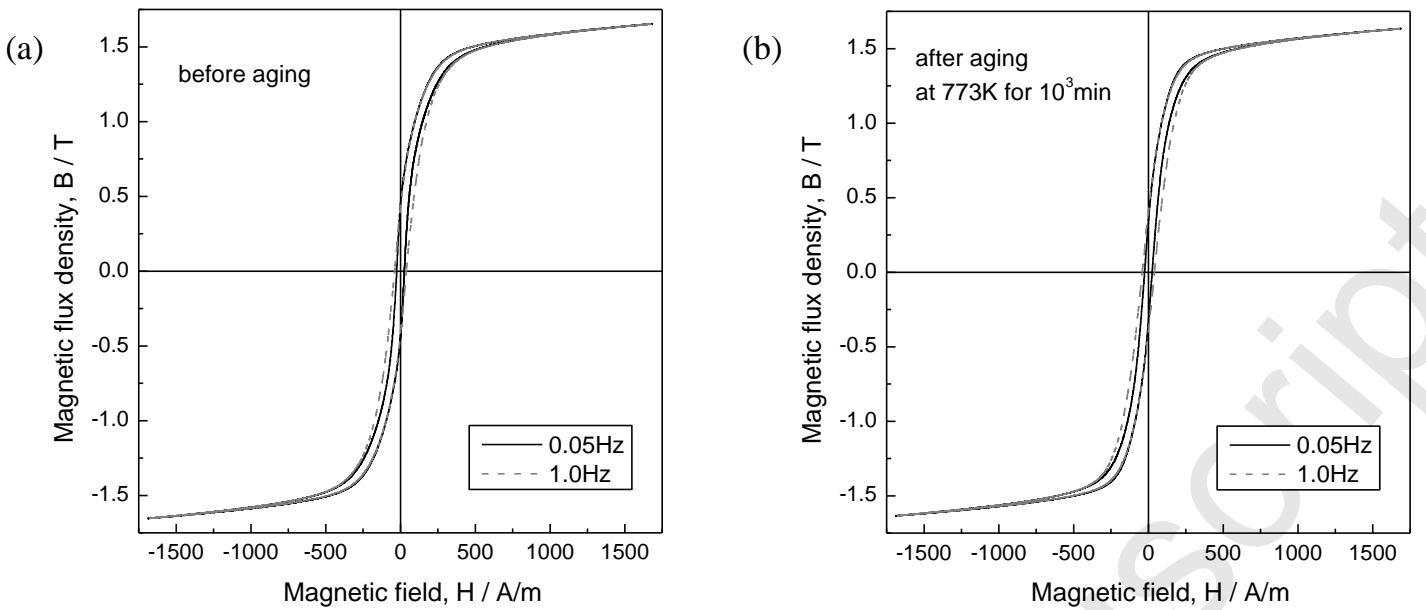

Fig. 4 Magnetic hysteresis loops of (a) unaged and (b) aged specimens.

Y. Kamada et al. FM034 


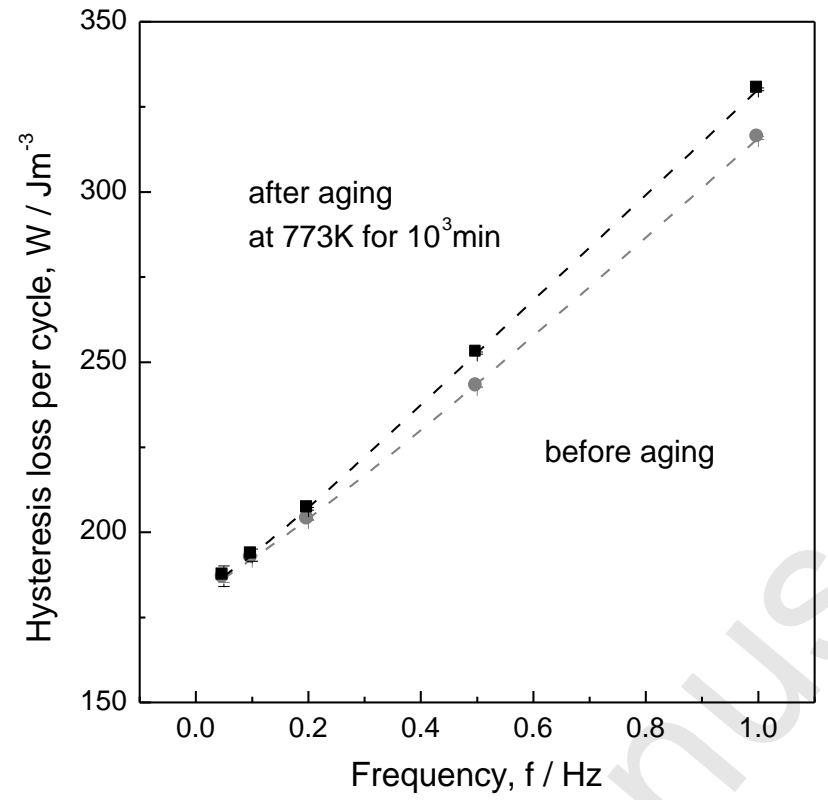

Fig. 5 Magnetic hysteresis loss as a function of frequency.

Y. Kamada et al. FM034 


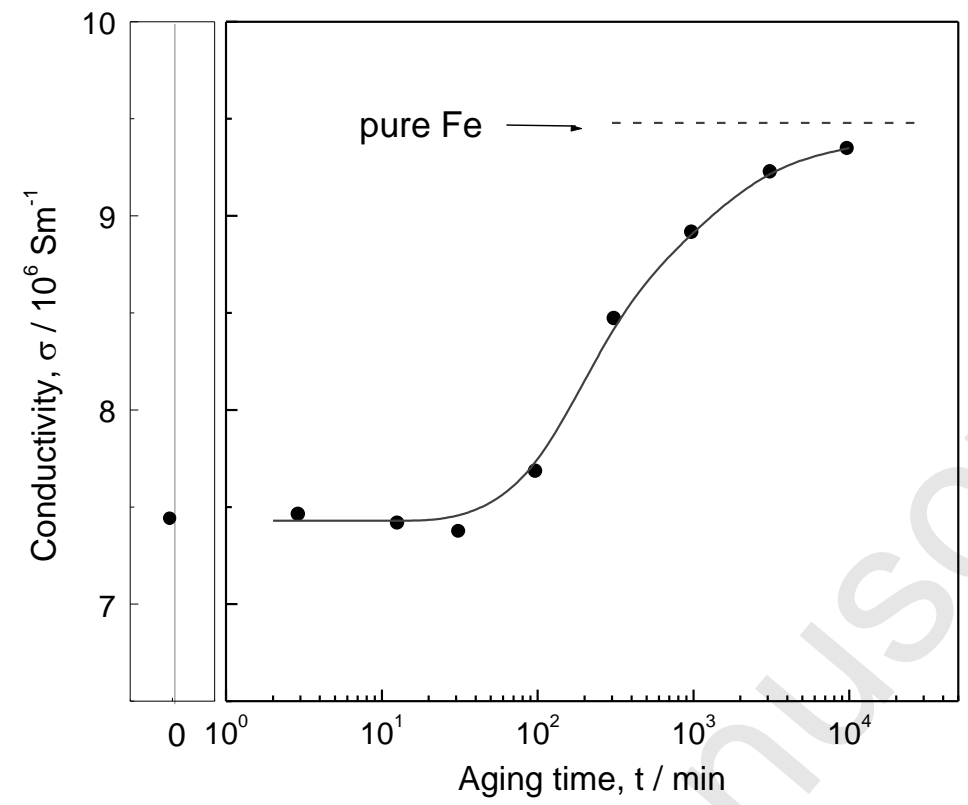

Fig. 6 Aging time dependence of conductivity.

Y. Kamada et al. FM034 